\title{
Prolonged prehospital tourniquet placement associated with severe complications: a case report
}

\author{
Christian Malo, MD, $\mathrm{MSc}^{*}$; Bruno Bernardin, $\mathrm{MD}^{*}$; Joe Nemeth, MD*; Kosar Khwaja, MD, MBA
}

Keywords: Tourniquet, Prehospital, Extremity Injury,

Ischemia, Hemorrhage, Gunshot Wounds

\section{INTRODUCTION}

Emergency tourniquet application to arrest hemorrhage in major limb trauma, particularly in the military context, has been shown to be a life-saving manoeuvre. ${ }^{1-3}$ Due to the potential for significant complications (including clots, myonecrosis, pain, palsy, abscess, blisters, contusions, abrasions, renal failure, compartment syndrome, and amputation $)^{4}$ and the paucity of evidence of its role in the non-military context, controversy persists regarding tourniquet use. We describe a civilian case in which improvised tourniquets were applied to an extremity for 17 hours following a penetrating lower limb injury in a remote area of Quebec.

\section{CASE REPORT}

A 38-year-old man was involved in a shooting in a small remote Quebec village. The patient sustained a gunshot wound to the left thigh at 8:15 pm and was immediately transported to the community clinic where a nurse applied compression over the bleeding wound. Following application of the dressing, medical consultation was sought over the phone from a physician of a nearby village. The nurse was instructed to apply a tourniquet proximal to the bleeding wound and a pressure dressing. Because the first tourniquet (a leather belt) failed to control the bleeding, another improvised tourniquet (a seatbelt) was placed distal to the first one. The two tourniquets were in place by $8: 30 \mathrm{pm}$, and hemostasis was achieved.

At 9:15 pm, the patient's hemodynamic status deteriorated (blood pressure 90/50 $\mathrm{mm} \mathrm{Hg}$, heart rate 113 beats/min). Because no blood products were available, the patient was administered crystalloids. At 10:20 pm, the trauma team leader at our institution was contacted by the local physician in the closest village, and, at 2:30 am, the local physician had arrived at the patient's bedside with blood products. Due to continued hemodynamic compromise and agitation, the patient was intubated, started on a norepinephrine infusion, and administered five units of packed red blood cells and three units of fresh frozen plasma. The left lower extremity distal to the tourniquets was reportedly cold, cyanotic, and edematous, at this time. The patient responded to fluid resuscitation, and the norepinephrine was gradually weaned.

The patient was transported from the remote village to the nearest community hospital, arriving at 6:00 am. The first venous blood gas measurement showed a $\mathrm{pH}$ of $6.91, \mathrm{pCO}_{2}$ of $51 \mathrm{~mm} \mathrm{Hg}, \mathrm{HCO}_{3} 10 \mathrm{mEq} / \mathrm{L}$, lactate $8.5 \mathrm{mmol} / \mathrm{L}$, and hemoglobin $122 \mathrm{~g} / \mathrm{L}$. At $8: 30 \mathrm{am}$, the repeat venous blood gas measurement showed $\mathrm{pH}$ 7.15, $\mathrm{pCO}_{2} 54 \mathrm{~mm} \mathrm{Hg}, \mathrm{HCO}_{3} 18 \mathrm{mEq} / \mathrm{L}$, base excess of -9.2 , and lactate $6.2 \mathrm{mmol} / \mathrm{L}$. At $9: 00 \mathrm{am}$, the patient was transported by fixed-wing air ambulance to our tertiary trauma care facility, $1633 \mathrm{~km}$ away.

The patient remained hemodynamically stable during transport and arrived at our facility at $1: 00 \mathrm{pm}$. On arrival, the left lower limb was edematous, cold, cyanotic, and pulseless (Figures 1 and 2). A venous blood gas measurement showed $\mathrm{pH} 7.41, \mathrm{pCO}_{2} 29 \mathrm{~mm} \mathrm{Hg}, \mathrm{HCO}_{3}$ $18 \mathrm{mEq} / \mathrm{L}$, lactate $2.1 \mathrm{mmol} / \mathrm{L}$, hemoglobin $112 \mathrm{~g} / \mathrm{L}$, and an international normalized ratio of 1.27 . Plain radiography of the pelvis and left femur did not show a bullet or fracture. The patient was immediately taken to the operating theatre, and both tourniquets were sequentially removed (total tourniquet time was more than 17 hours). The leg appeared to be demarcated at the knee joint

From the *Departments of Emergency Medicine; and TSurgery, Trauma Program, McGill University Health Centre, Montreal, OC.

Correspondence to: Dr. Christian Malo, MUHC Trauma Program, McGill University Health Centre, 1650 Cedar Avenue, L9.411, Montreal, OC H3G 1A4; Email: christian.malo@ mail.mcgill.ca

$\mathrm{CM}, \mathrm{BB}, \mathrm{KK}$ and JN participated in writing and review of the final manuscript. CM takes responsibility for the paper as a whole.

(C) Canadian Association of Emergency Physicians CJEM 2015;17(4):443-446

DOI 10.1017/cem.2014.44 


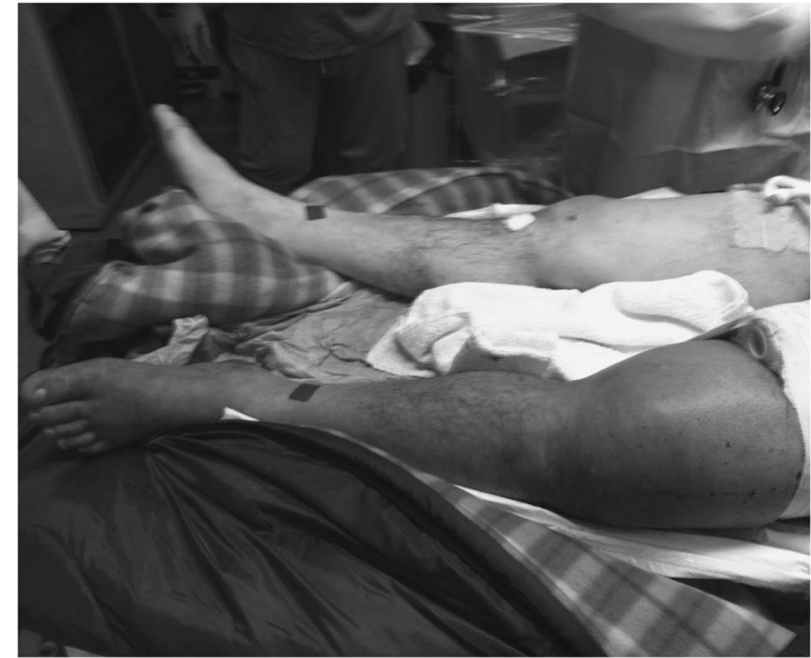

Figure 1. The patient lower limbs on arrival at our trauma center. Note the "paramedic belt" used as an improvised tourniquet. Part of the leather belt used as another improvised tourniquet can also be seen.

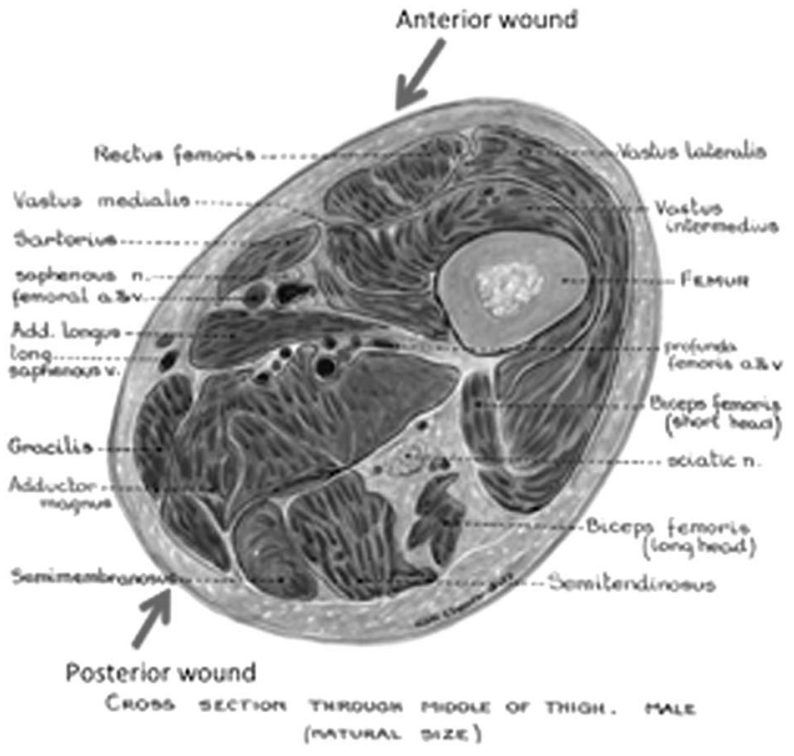

Figure 2. Anatomic cross section of the left thigh. The two wounds are illustrated.

down. Therefore, the femoral artery and vein were suture-ligated just above the knee, and an above-knee amputation was undertaken. Then, the two tourniquets and pressure dressings were removed, and anterior and posterior thigh penetrating wounds were identified. A counter incision was made at the injury site on the medial aspect of the thigh. The femoral superficial artery and vein were transected approximately half of their circumferences. Both vessels were oversewed. After this, complete hemostasis was achieved. The patient was transferred to the intensive care unit and treated with hemofiltration for rhabdomyolysis (serum creatine kinase $103,649 \mathrm{IU} / \mathrm{L})$. The patient subsequently made an uneventful recovery and was transferred to a rehabilitation centre.

\section{DISCUSSION}

This case illustrates the potential use of tourniquets as a life-saving measure in civilian settings. It also highlights the challenges faced by local health care providers in remote locations.

To control exsanguination, tourniquets have been used for centuries. Since World War II, their utility in the military context has suggested a role in the civilian, prehospital context. When compared to manual compression, the advantages of tourniquets are 1) relative ease of application, 2) freedom for the medical provider's hands to perform other tasks, and 3) provision of more reliable pressure over time. There exist inherent disadvantages: 1) interference with both arterial and venous circulation, 2) risk of nerve injuries and skin necrosis, and 3) limb ischemia and possible reperfusion injury if in situ for a prolonged period of time.

A review of tourniquet use in the civilian prehospital setting during the last 5 years identified three prior case reports (Table 1). Fludger and Bell ${ }^{5}$ described a civilian case with a prolonged tourniquet time: a 67-year-old man who sustained an above-knee amputation after his right foot was caught in an agricultural machine. A pneumatic tourniquet was applied until the patient was transported by helicopter to the referring trauma centre $500 \mathrm{~km}$ away. On arrival, the limb was clearly not salvageable. The tourniquet had stayed in place for 6 hours.

Recent literature from the military environment includes a case-control retrospective study of military casualties with significant traumatic injury to an extremity during Operation Freedom in Iraq by Beekley et al. ${ }^{8}$ They identified 67 patients who arrived at the hospital with prehospital tourniquets and did not find a survival benefit, although they reported that $85 \%$ of the tourniquets had achieved hemostasis. The relatively short tourniquet time (average of 70 minutes) may explain, in part, the absence of any adverse effects of tourniquet use in their report. Kragh et al. ${ }^{4}$ conducted an observational study over 1 year in Iraq and included 499 patients with tourniquet placement either in the prehospital setting or emergency department $(86 \% \mathrm{v}$. $14 \%$ ). The overall survival rate was $87 \%$, and survival 


\begin{tabular}{|c|c|c|c|c|}
\hline $\begin{array}{l}\text { First author, country, year } \\
\text { of publication }\end{array}$ & $\begin{array}{l}\text { Age (years), } \\
\text { gender }\end{array}$ & Mechanism of injury & $\begin{array}{l}\text { Type of tourniquet, total } \\
\text { time of tourniquet use }\end{array}$ & Outcome \\
\hline Fludger, Australia, $2009^{5}$ & 67, male & $\begin{array}{l}\text { Right leg crushed in an } \\
\text { agricultural machine in a remote } \\
\text { area (500 km from the referring } \\
\text { trauma facility) }\end{array}$ & $\begin{array}{l}\text { Pneumatic tourniquet, } \\
6 \text { hours }\end{array}$ & Above-knee amputation \\
\hline $\begin{array}{l}\text { Mullins, United States, } \\
2009^{6}\end{array}$ & 46, male & Gunshot wound to the right thigh & $\begin{array}{l}\text { Improvised tourniquet } \\
\text { (leather belt), } \\
27 \text { minutes }\end{array}$ & $\begin{array}{l}\text { Femoral artery repaired, patient } \\
\text { walking independently }\end{array}$ \\
\hline $\begin{array}{l}\text { Sims, United States, } \\
2012^{7}\end{array}$ & 72, male & $\begin{array}{l}\text { Motor vehicle crash, crushing left } \\
\text { arm, which was resting in the } \\
\text { open window }\end{array}$ & Unspecified, unspecified & $\begin{array}{l}\text { Saved limb, following five } \\
\text { operations }\end{array}$ \\
\hline
\end{tabular}

was higher with prehospital tourniquet application $(89 \%$ v. $78 \%)$ and with application before onset of shock ( $96 \%$ v. $4 \%$ ); $1.5 \%$ of patients sustained palsies at the level of the tourniquet, and $0.4 \%$ had a major limb shortening secondary to the tourniquet. A prospective observational study in Afghanistan identified that 97\% of the military tourniquets applied prior to hospital arrival were deemed indicated and that $94 \%$ had been placed correctly. ${ }^{9}$ In 2012, the Eastern Association for the Surgery of Trauma Guidelines made the use of tourniquet a level-3 evidence when compression measures are not able to control the bleeding. ${ }^{10}$ Finally, in the ninth edition of the Advanced Trauma Life Support (ATLS) book, the American College of Surgeons Committee on Trauma states that, in the context of major arterial bleeding, "the judicious use of a tourniquet may be helpful and life-saving."

Recently, this committee published guidelines for prehospital tourniquet use, based mostly on data from military studies. The committee made a strong recommendation (quality of evidence: moderate) for the use of tourniquets in the prehospital setting for the control of significant extremity hemorrhage if direct pressure is ineffective or impractical. ${ }^{12}$ There are no absolute contraindications to tourniquet placement. Improvised tourniquets tend to apply pressure unevenly and often have sharp edges. These increase the risk for underlying tissue injury and may partially occlude arterial flow and increase venous pressure, which may increase hemorrhage. ${ }^{13}$ Examples of suboptimal improvised tourniquets include belts and similar straps, elastic bandages, or sphygmomanometer cuffs. We believe that commercial tourniquets should be used when available because they are easy to apply in less than 1 minute and are not prone to loosening. Tourniquets should be placed $5-8 \mathrm{~cm}$ above the most proximal bleeding wound and should never be placed over an articulation or an impaled object. Based on pneumatic tourniquet use in elective orthopaedic surgery, tourniquet times less than 2 hours are generally safe. ${ }^{14,15}$ In the military context, tourniquet times longer than 4 , or sometimes even 8 , hours has not necessarily resulted in amputation. ${ }^{16-19}$ Although no guidelines exist regarding the safe duration of tourniquet application, we recommend that tourniquets be removed as soon as possible.

If used for a prolonged period, the use should be reassessed frequently (every 30 minutes). Unless the patient is still hemodynamically unstable, the situation is unstable, or insufficient personnel are available, direct pressure or pressure dressing can be applied to the wounds and the tourniquets released but left in place. If significant bleeding reappears, the tourniquet can be retightened.

Tourniquets should be removed in a controlled and monitored setting, especially after prolonged application. Before removal, physicians should be cognizant of the possibility of a sudden cardiovascular collapse attributed to reperfusion and the release into the systemic circulation of toxic cytokines.

\section{CONCLUSION}

Tourniquet use in civilian prehospital setting remains highly debated, but it may be life-saving. In the case reported here, two improvised tourniquets were needed to control a hemorrhage but at the cost of an aboveknee amputation.

Competing interests: None declared. 


\section{REFERENCES}

1. Kragh JF Jr, Beebe DF, O'Neill ML, et al. Performance improvement in emergency tourniquet use during the Baghdad surge. Am 7 Emerg Med 2013;31(5):873-5, doi: 10.1016/j.ajem.2012.11.030. PMID: 23481155.

2. King DR, van der Wilden G, Kragh JF Jr, et al. Forward assessment of 79 prehospital battlefield tourniquets used in the current war. 7 Spec Oper Med 2012;12(4):33-8. PMID: 23536455

3. Kragh JF Jr, Littrel ML, Jones JA, et al. Battle casualty survival with emergency tourniquet use to stop limb bleeding. 7 Emerg Med 2011;41(6):590-7.

4. Kragh JF Jr, O'Neill ML, Walters TJ, et al. Minor morbidity with emergency tourniquet use to stop bleeding in severe limb trauma: research, history, and reconciling advocates and abolitionists. Mil Med 2011;176(7):817-23. PMID: 22128725.

5. Fludger S, Bell A. Tourniquet application in a rural Queensland HEMS environment. Air Med 7 2009;28(6): 291-3, doi: 10.1016/j.amj.2009.06.002. PMID: 19896580.

6. Mullins J, Harrahill M. Use of a tourniquet after a gunshot wound to the thigh. 7 Emerg Nurs 2009;35(3):265-7, doi: 10.1016/j.jen.2009.01.008. PMID: 19446140.

7. Sims C, Polk T. Rollover car crash almost costs driver his life, limb. 7 Emerg Med Serv 2012;37(9):30-1. PMID: 23342696.

8. Beekley AC, Sebesta JA, Blackbourne LH, et al. Prehospital tourniquet use in Operation Iraqi Freedom: effect on hemorrhage control and outcomes. 7 Trauma 2008;64(2 Suppl): S28-S37; discussion S37, doi: 10.1097/TA.0b013e318160937e.

9. Lairet JR, Bebarta VS, Burns CJ, et al. Prehospital interventions performed in a combat zone: a prospective multicenter study of 1,003 combat wounded. 7 Trauma Acute Care Surg 2012;73(2 Suppl 1):S38-42. PMID: 22847092.

10. Fox N, Rajani RR, Bokhari F, et al. Evaluation and management of penetrating lower extremity arterial trauma: an Eastern
Association for the Surgery of Trauma practice management guideline. 7 Trauma Acute Care Surg 2012;73(5):S315-20. PMID: 23114487, doi: 10.1097/TA.0b013e31827018e4.

11 American College of Surgeons Committee on Trauma. Advanced trauma life support (ATLS): ninth edition. 7 Trauma Acute Care Surg 2013; 74(5):1363-6. PMID: 23609291. doi: 10.1097/TA.0b013e31828b82f5.

12. Bulger ME, Snyder D, Schoelles K, et al. An evidence-based prehospital guideline for external hemorrhage control: American College of Surgeons Committee on Trauma. Prehosp Emerg Care 2014;18:163-73. PMID: 24641269, doi: 10.3109/10903127.2014.896962.

13. Doyle GS, Taillac PP. Tourniquets: a review of current use with proposals for expanded prehospital use. Prehosp Emerg Care 2008;12:241-56. PMID: 18379924, doi: 10.1080/ 10903120801907570 .

14. Wakai A, Winter DC, Street JT, et al. Pneumatic tourniquets in extremity surgery. I Am Acad Orthop Surg 2001;9:345-51. PMID: 11575914.

15. Lee C, Porter KM, Hodgetts TJ. Tourniquet use in the civilian prehospital setting. Emerg Med 7 2007;24:584-7. PMID: 17652690, doi: 10.1136/emj.2007.046359.

16. Kragh JF Jr, Walters TJ, Baer DG, et al. Survival with emergency tourniquet use to stop bleeding in major limb trauma. Ann Surg 2009;249(1):1-7. PMID: 19106667, doi: 10.1097/SLA.0b013e31818842ba.

17. Tien HC, Jung V, Rizoli SB, et al. An evaluation of tactical combat casualty care interventions in a combat environment. 7 Am Coll Surg 2008;207(2):174-8. PMID: 18656043, doi: 10.1016/j.jamcollsurg.2008.01.065.

18. Wolf LH, Adkins TF. Tourniquet problems in war injuries. Bull U S Army Med Dep 1945;87:77-84.

19. Kragh JF Jr, Baer DG, Walters TJ. Extended (16-hour) tourniquet application after combat wounds: a case report and review of the current literature. 7 Orthop Trauma 2007;21(4):274-8. PMID: 17414556. 